\section{CardioRenal Medicine}

\title{
Evaluation of the CRUSADE Risk Score for Predicting Major Bleeding in Patients with Concomitant Kidney Dysfunction and Acute Coronary Syndromes
}

\author{
Marianela Sánchez-Martínez ${ }^{a}$ Pedro J. Flores-Blanco ${ }^{a}$ \\ Ángel A. López-Cuencab María J. Sánchez-Galián ${ }^{a}$ \\ Miriam Gómez-Molina ${ }^{a}$ Francisco Cambronero-Sánchez ${ }^{d}$ \\ Esther Guerrero-Pérez ${ }^{a} \quad$ Mariano Valdés ${ }^{a, c}$ James L. Januzzi ${ }^{e}$ \\ Sergio Manzano-Fernández ${ }^{\text {a, c }}$ \\ a Division of Cardiology, University Hospital Virgen de la Arrixaca, School of Medicine, \\ ${ }^{b}$ Department of Internal Medicine, Hospital J.M. Morales Meseguer, and ' University of \\ Murcia, Murcia, and d Department of Internal Medicine, Hospital Los Arcos del Mar Menor, \\ San Javier, Spain; e Division of Cardiology, Massachusetts General Hospital, Boston, MA, USA
}

\section{Keywords}

Acute coronary syndrome $\cdot$ Bleeding $\cdot$ Kidney dysfunction

\begin{abstract}
Background: Kidney dysfunction (KD) has been associated with increased risk for major bleeding (MB) in patients with acute coronary syndromes (ACS) and may be in part related to an underuse of evidence-based therapies. Our aim was to assess the predictive ability of the Can Rapid risk stratification of Unstable angina patients Suppress ADverse outcomes with Early implementation of the ACC/AHA guidelines (CRUSADE) risk score in patients with concomitant ACS and chronic kidney disease. Methods: We conducted a retrospective analysis of a prospective registry including 1,587 ACS patients. In-hospital MB was prospectively recorded according to the CRUSADE and Bleeding Academic Research Consortium (BARC) criteria. KD was defined as an estimated glomerular filtration rate $<60 \mathrm{~mL} / \mathrm{min} / 1.73 \mathrm{~m}^{2}$. Results: The predictive ability of the CRUSADE risk score was assessed by discrimination and calibration analyses. A total of 465 (29\%) subjects had KD. In multivariate logistic regression analyses, we found high CRUSADE risk score values to be associated with a higher rate of in-hospital $M B$; however, among patients with $K D$, it was not associated with BARC MB. Regardless of the $M B$ definition, the predictive ability of the CRUSADE score in patients with KD was lower: area under the curve (AUC) 0.71 versus $0.79, p=0.03$ for CRUSADE MB and AUC 0.65 versus 0.75 , $p=0.02$ for BARC MB. Hosmer-Lemeshow analyses showed a good calibration in all renal
\end{abstract}

Marianela Sánchez-Martínez, MD

E-Mail marianela_com@ @otmail.com 
Sánchez-Martínez et al.: CRUSADE Score in Kidney Dysfunction Patients

function subgroups for both MB definitions (all $p$ values $>0.3$ ). Conclusions: The CRUSADE risk score shows a lower accuracy for predicting in-hospital MB in KD patients compared to those without KD.

(C) 2017 S. Karger AG, Basel

\section{Introduction}

The use of more potent antithrombotic agents and invasive strategies has improved the outcomes in acute coronary syndrome (ACS) patients [1]. However, the beneficial reduction in ischemic events is realized only at the cost of excess major bleeding (MB) complications; such bleeding has emerged as a powerful and independent risk factor for adverse events [2]. Moreover, despite the increased risk for MB associated with current therapies, the absolute risk for MB has decreased [3]. This downward trend in MB complications may be partially related to the development of accurate risk scores for predicting bleeding that lead to refine the antithrombotic therapy and the optimal management of these patients [4]. Along this line, current ACS guidelines [5, 6] recommend the use of the Can Rapid risk stratification of Unstable angina patients Suppress ADverse outcomes with Early implementation of the ACC/ AHA guidelines (CRUSADE) score to identify patients at higher risk for in-hospital MB complications [7]. This score was initially developed in a large cohort of patients with nonST-segment-elevation ACS and subsequently validated in ST-segment-elevation ACS patients [8]. Among ACS patients, kidney dysfunction (KD) is common and represents an established risk factor for bleeding complications [7-9]. Patients with KD are often older, with more comorbidities, and have an increased risk of both ischemic and bleeding complications [9, 10]. Therefore, the management of these patients is frequently challenging for clinicians, and accurate balancing of ischemic and bleeding risk stratification is highly desirable. Previous studies have reported an underuse of evidence-based therapies in KD patients, which may be in part related to their higher MB risk [11]. Then, given the clinical relevance of appropriate bleeding risk stratification in KD patients, the aim of our study was to assess the performance of the CRUSADE risk score in predicting in-hospital MB complications in an unselected and contemporary cohort of patients with KD admitted with ACS, and to compare it to patients with normal kidney function.

\section{Methods}

The present study is a retrospective analysis of a tertiary university hospital prospective registry. Between January 2012 and July 2015, 1,587 consecutive patients with a diagnosis of ACS were included. Patients who underwent coronary artery bypass graft $(n=83)$ or those with missing risk score data were excluded from the analysis $(n=37)$. During the index hospitalization, data on demographic and clinical characteristics, medication as well as laboratory, electrocardiographic, echocardiographic, angiographic findings, and clinical complications were collected in detail using a standardized form. The clinical management decisions about each patient were decided by the cardiologist responsible.

The study endpoint was the occurrence of in-hospital MB, defined according to CRUSADE [7] and Bleeding Academic Research Consortium (BARC) criteria [12]. CRUSADE MB was defined as intracranial hemorrhage, documented retroperitoneal bleed, hematocrit drop of $\geq 12 \%$ (baseline to nadir), any red blood cell transfusion when baseline hematocrit was $\geq 28 \%$, or any red blood cell transfusion when baseline hematocrit was $<28 \%$ with witnessed bleed. For reasons of clinical relevance, BARC bleeding types 3-5 were defined as major MB: type 3a, overt bleeding plus hemoglobin drop of 3-5 g/dL, any transfusion with overt bleeding; type $3 \mathrm{~b}$, overt bleeding plus hemoglobin drop $5 \mathrm{~g} / \mathrm{dL}$, cardiac tamponade, bleeding requiring surgical intervention for control (excluding dental/nasal/skin/hemorrhoid), bleeding requiring intravenous vasoactive agents; type $3 \mathrm{c}$, intracranial hemorrhage (does not include microbleeds or hemorrhagic transfor- 


\section{CardioRenal Medicine}

\begin{tabular}{l|l}
\hline Cardiorenal Med 2017;7:179-187 \\
\hline DOI: 10.1159/000455102 & $\begin{array}{l}\text { @ 2017 S. Karger AG, Basel } \\
\text { www.karger.com/crm }\end{array}$ \\
\hline
\end{tabular}

Sánchez-Martínez et al.: CRUSADE Score in Kidney Dysfunction Patients

mation, but does include intraspinal bleeding), subcategories confirmed by autopsy or imaging or lumbar puncture, intraocular bleed compromising vision; type 5, fatal bleeding (type $5 \mathrm{a}$, probable; type $5 \mathrm{~b}$, definite). MB events were prospectively collected by 2 trained cardiologists (S.M.-F. and P.J.F.-B.) who also classified the type of MB. A third cardiologist (A.L.-C.) was consulted if there were discrepancies. All elements comprising the definitions of BARC and CRUSADE bleeding were included in our daily registry data collection. KD was defined as the presence of an estimated glomerular filtration rate (eGFR) $<60 \mathrm{~mL} / \mathrm{min} / 1.73 \mathrm{~m}^{2}$. eGFR was calculated with the CKD-EPI equation using serum creatinine at admission [13].

\section{Statistical Analysis}

Categorical variables are presented as frequency values, and continuous variables are presented as mean \pm standard deviation (SD) or as median and interquartile range. Categorized analyses were performed comparing patients with and without KD. Differences in baseline characteristics were compared using the Student $t$ test or the Mann-Whitney $\mathrm{U}$ test for continuous variables and the $\chi^{2}$ test or Fisher exact test for categorical variables. The independent effect of CRUSADE bleeding risk scores on MB was assessed by a multivariate binary logistic regression model. Variables associated with MB in univariate analyses $(p<0.05)$ were included in a multivariate prediction model. In order to avoid model overfitting and multicollinearity effects, we did not incorporate as independent covariates those variables included in the CRUSADE risk scores. The MB complications model included as covariates: atrial fibrillation or atrial flutter, high-sensitive troponin $\mathrm{T}$, chronic obstructive pulmonary disease, radial access, multivessel disease, percutaneous coronary intervention, and newer antiplatelet agent use. To assess the predictive ability of the CRUSADE bleeding risk score for predicting MB, we performed discrimination and calibration analyses. Receiver-operating characteristic (ROC) curves and their corresponding areas under the curve (AUC) were performed using binary logistic models. Comparisons between ROCs were made for both CRUSADE and BARC bleeding complications according to kidney function status. The method by DeLong et al. [14] was used to compare ROCs. To assess the calibration of the CRUSADE bleeding risk score, we used the Hosmer-Lemeshow (H-L) goodness-of-fit test [15]. The H-L test estimates a c-statistic based on the difference between the MB event values observed in reality and those predicted by the CRUSADE bleeding risk score for different risk groups. The smaller the statistical value, the better calibrated the model. A $p$ value $>0.05$ indicates that the model is well adjusted to the data and therefore is a good predictor of patients' probability of MB. All $p$ values $<0.05$ were accepted as statistically significant. Statistical analysis was performed using statistical software (STATA 13.0 for Windows).

\section{Results}

The study population consisted of 1,587 patients with ACS (Table 1). The mean eGFR was $73 \pm 24 \mathrm{~mL} / \mathrm{min} / 1.73 \mathrm{~m}^{2}$, and 465 (29\%) patients had KD (eGFR $<60 \mathrm{~mL} / \mathrm{min} / 1.73 \mathrm{~m}^{2}$ ). The characteristics of the study population according to kidney function status are also shown in Table 1. Compared to patients without KD, those with KD were older, more frequently female, and had more comorbidities.

The mean CRUSADE bleeding risk score value was $30 \pm 16$ points. Based on the CRUSADE bleeding risk score bleeding risk categories, 486 (31\%) patients had a very low-risk, 352 (22\%) had a low risk, 320 (20\%) had a moderate risk, 235 (15\%) had a high risk, and 194 $(12 \%)$ had a very high risk. Patients with KD had a higher CRUSADE bleeding risk score (46 \pm 13 vs. $24 \pm 13, p<0.001$ ). However, these patients underwent invasive coronary angiography less frequently and were less often revascularized than patients without KD. As expected, the use of drug-eluting stents and potent antiplatelet agents (glycoprotein IIb/IIIa inhibitors, aspirin, clopidogrel, and prasugrel) were less frequent in KD patients as compared with patients without KD. Regarding anticoagulant agents, enoxaparin was more frequently used in KD patients.

During the index hospitalization, a total of $34(2.1 \%)$ patients had CRUSADE MB and 37 (2.3\%) had BARC MB: 18 (49\%) type 3a, 16 (43\%) type 3b, and 3 (8\%) type 5b. Compared to patients without KD, those with KD had a higher in-hospital MB rate $(1.6 \%$ [ $n=18]$ vs. $4.1 \%$ 
Table 1. Baseline study population characteristics according to kidney function status

\begin{tabular}{|c|c|c|c|c|}
\hline & \multirow{2}{*}{$\begin{array}{l}\text { Whole population } \\
(N=1,587)\end{array}$} & \multicolumn{2}{|c|}{$\mathrm{eGFR}<60 \mathrm{~mL} / \mathrm{min} / 1.73 \mathrm{~m}^{2}$} & \multirow[t]{2}{*}{$p$} \\
\hline & & no $(n=1,122)$ & yes $(n=465)$ & \\
\hline Age, years & $67 \pm 13$ & $64 \pm 13$ & $75 \pm 10$ & $<0.001$ \\
\hline Sex, male & $1,143(72)$ & $855(76)$ & $288(62)$ & $<0.001$ \\
\hline Diabetes mellitus & $728(46)$ & $461(41)$ & 267 (57) & $<0.001$ \\
\hline Hypertension & $1,150(73)$ & $735(66)$ & $415(89)$ & $<0.001$ \\
\hline Hyperlipidemia & $1,175(74)$ & $811(72)$ & $364(78)$ & 0.013 \\
\hline Current smoking & $484(37)$ & 419 (37) & $65(14)$ & $<0.001$ \\
\hline Previous STE-ACS & 246 (16) & $167(15)$ & $79(17)$ & 0.301 \\
\hline Previous NSTE-ACS & $383(24)$ & $220(20)$ & $163(35)$ & $<0.001$ \\
\hline Previous PCI & $475(30)$ & $293(26)$ & $182(39)$ & $<0.001$ \\
\hline Previous CABG & $78(5)$ & $44(4)$ & $34(7)$ & 0.004 \\
\hline Chronic heart failure & $83(5)$ & $35(3)$ & $48(10)$ & $<0.001$ \\
\hline Previous ischemic stroke & $165(10)$ & $80(7)$ & $85(18)$ & $<0.001$ \\
\hline Previous hemorrhagic stroke & $22(1)$ & $9(1)$ & $13(3)$ & 0.002 \\
\hline Peripheral artery disease & $121(8)$ & $59(5)$ & $62(13)$ & $<0.001$ \\
\hline Atrial fibrillation/flutter & $231(15)$ & $108(10)$ & $123(27)$ & $<0.001$ \\
\hline Chronic oral anticoagulation & $134(8)$ & $64(6)$ & $70(15)$ & $<0.001$ \\
\hline Malignancy & $87(6)$ & $54(5)$ & $33(7)$ & 0.069 \\
\hline COPD & $161(10)$ & $110(10)$ & $51(11)$ & 0.485 \\
\hline Cardiac arrest & $37(2)$ & $27(2)$ & $10(2)$ & 0.758 \\
\hline SBP, mm Hg & $135 \pm 28$ & $135 \pm 28$ & $135 \pm 30$ & 0.954 \\
\hline Heart rate, beat/min & $77 \pm 19$ & $77 \pm 18$ & $78 \pm 21$ & 0.176 \\
\hline Dynamic ECG changes & $754(48)$ & $547(49)$ & $207(45)$ & 0.117 \\
\hline eGFR, $\mathrm{mL} / \mathrm{min} / \mathrm{m}^{2}$ & $73 \pm 24$ & $85 \pm 15$ & $42 \pm 13$ & $<0.001$ \\
\hline Hemoglobin, g/dL & $13.8 \pm 1.9$ & $14.1 \pm 1.8$ & 12.91 .9 & $<0.001$ \\
\hline hs-cTnT, pg/mL & $47(16-226)$ & $40(13-199)$ & $62(25-336)$ & $<0.001$ \\
\hline LVEF & $54 \pm 12$ & $55 \pm 12$ & $52 \pm 14$ & $<0.001$ \\
\hline STEMI & $521(33)$ & $396(36)$ & $125(27)$ & $<0.001$ \\
\hline NSTEMI & $627(40)$ & $421(38)$ & $206(44)$ & \\
\hline Unstable angina & $336(21)$ & $248(22)$ & $88(19)$ & \\
\hline Undetermined infarction & $103(7)$ & $57(5)$ & $46(10)$ & \\
\hline Coronary angiography & $1,400(88)$ & $1,036(93)$ & $364(78)$ & $<0.001$ \\
\hline Radial access & $1,146(72)$ & 889 (79) & $257(55)$ & $<0.001$ \\
\hline Left main or 3 vessel disease & $247(16)$ & $150(13)$ & $97(21)$ & $<0.001$ \\
\hline PCI & $1,132(71)$ & $849(76)$ & $283(61)$ & $<0.001$ \\
\hline Drug eluting stent & $931(59)$ & $716(64)$ & $215(46)$ & $<0.001$ \\
\hline Thrombolytic & $55(3)$ & $46(4)$ & $9(2)$ & 0.032 \\
\hline Gp IIb/IIIa inhibitors & $232(15)$ & 193 (17) & $39(8)$ & $<0.001$ \\
\hline Enoxaparin & $901(57)$ & $580(52)$ & $321(69)$ & $<0.001$ \\
\hline Fondaparinux & $228(14)$ & $173(15)$ & $55(12)$ & 0.063 \\
\hline Unfractionated heparin & $1,352(85)$ & $1,009(90)$ & $343(74)$ & $<0.001$ \\
\hline \multicolumn{5}{|l|}{ Enoxaparin/ } \\
\hline unfractionated heparin switch & $721(45)$ & $497(44)$ & $224(48)$ & 0.158 \\
\hline Bivalirudin & $2(0.1)$ & $2(0.2)$ & $0(0)$ & 1.000 \\
\hline Aspirin & 1,552 (98) & 1,106 (99) & 446 (96) & 0.001 \\
\hline Clopidogrel & $1,276(80)$ & $893(80)$ & $382(82)$ & 0.243 \\
\hline Prasugrel & $233(15)$ & 200 (18) & $33(7)$ & $<0.001$ \\
\hline Ticagrelor & 199 (13) & 155 (14) & $44(10)$ & 0.017 \\
\hline
\end{tabular}

Data are expressed as mean \pm standard deviation, median (interquartile range), and number (\%). STE-ACS, ST-segment-elevation acute coronary syndrome; NSTE-ACS, non-STE-ACS; PCI, percutaneous coronary intervention; CABG, coronary artery bypass graft; COPD, chronic obstructive pulmonary disease; SBP, systolic blood pressure; ECG, electrocardiography; eGFR, estimated glomerular filtration rate; hs-cTnT, high-sensitive cardiac troponin T; LVEF, left ventricular ejection fraction; Gp, glycoprotein; STEMI, ST-segment-elevation myocardial infarction; NSTEMI; non-STEMI. 


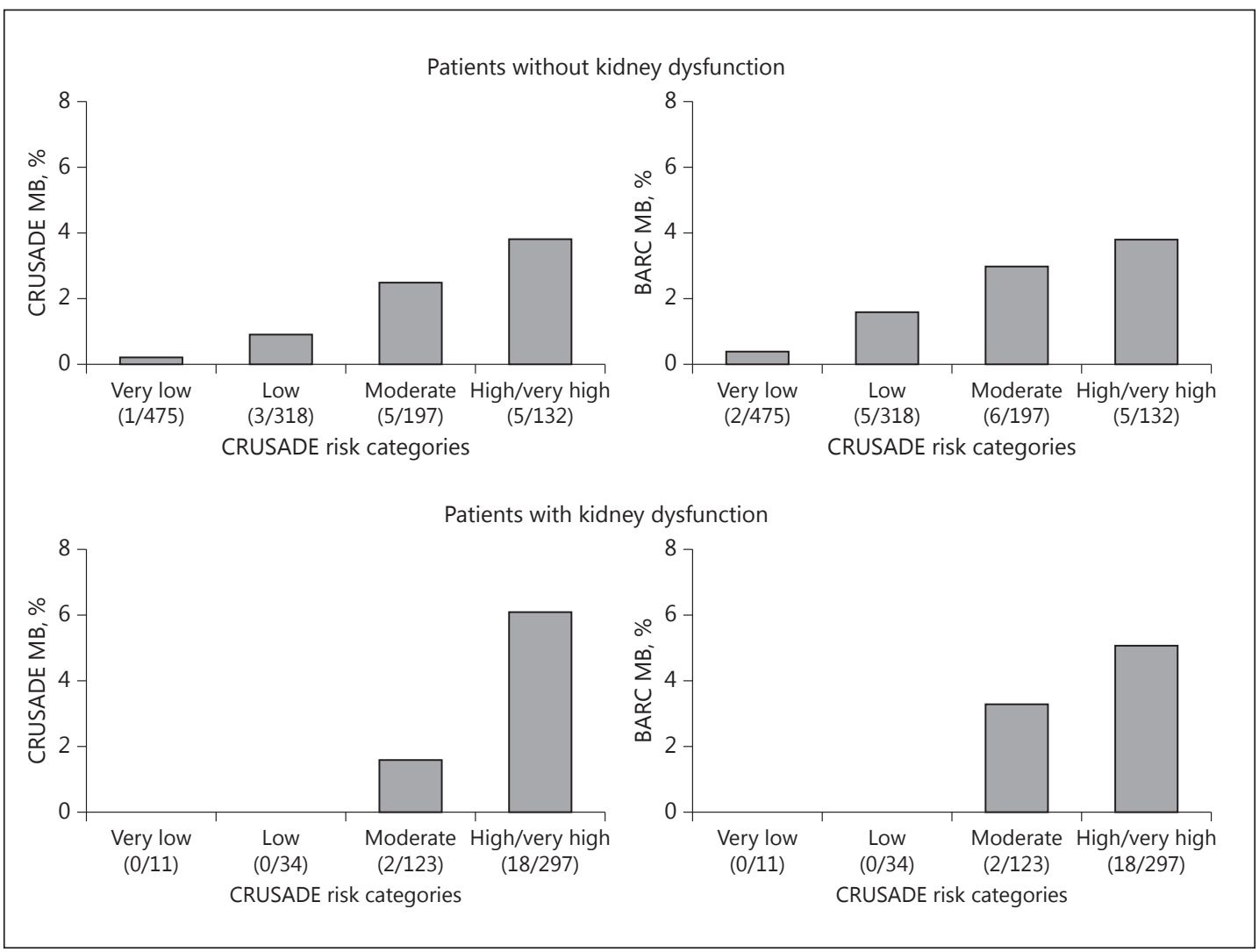

Fig. 1. Rates of in-hospital MB across the CRUSADE risk categories according to kidney function status.

[ $n=19], p=0.003$ for BARC MB and 1.2\% [ $n=14]$ vs. $4.3 \%[n=20], p<0.001$ for CRUSADE MB). Figure 1 shows an increase in both CRUSADE and BARC bleeding complications with increasing CRUSADE risk categories regardless of kidney function status. Moreover, in multivariate logistic regression analysis, we found high CRUSADE risk score values to be associated with a higher rate of in-hospital MB, but among patients with KD, it was not associated with BARC MB (Table 2). All independent predictors for MB in multivariate analyses are detailed in online supplementary Table 1 (www.karger.com/doi/10.1159/000455102).

Finally, to assess the accuracy of the CRUSADE bleeding risk score for predicting MB in patients with and without KD, we compared ROCs for both CRUSADE and BARC bleeding criteria according to kidney function status. Regardless of the MB definition, the predictive ability of the CRUSADE bleeding risk score in patients with KD was lower than in patients without KD (Fig. 2a, b): AUC 0.71 (95\% CI 0.60-0.86) versus AUC 0.79 (95\% CI 0.70-0.88), $p=0.032$ for CRUSADE MB and AUC 0.65 (95\% CI 0.51-0.79) versus AUC 0.75 (95\% CI $0.66-$ 0.84 ), $p=0.024$ for BARC MB. The H-L analyses showed a good calibration in all renal function subgroups for both MB definitions (all H-L $p$ values $>0.3$ ).

\section{Discussion}

In the present study, the CRUSADE bleeding risk score showed a lower predictive performance among KD patients compared to those with normal kidney function in the setting of ACS. Moreover, we found high CRUSADE risk score values to be associated with a higher rate 
Sánchez-Martínez et al.: CRUSADE Score in Kidney Dysfunction Patients

C) 2017 S. Karger AG, Basel

www.karger.com/crm

Table 2. Multivariate logistic regression analyses for predicting major bleeding complications

\begin{tabular}{|c|c|c|c|c|c|c|c|c|}
\hline & \multicolumn{4}{|c|}{ BARC major bleeding } & \multicolumn{4}{|c|}{ CRUSADE major bleeding } \\
\hline & \multicolumn{2}{|l|}{ univariate } & \multicolumn{2}{|l|}{ multivariate } & \multicolumn{2}{|l|}{ univariate } & \multicolumn{2}{|l|}{ multivariate } \\
\hline & OR & $p$ & OR & $p$ & OR & $p$ & OR & $p$ \\
\hline \multicolumn{9}{|l|}{ Whole population } \\
\hline CRUSADE $(\times$ point $)$ & $1.05(1.03-1.07)$ & $<0.001$ & $1.05(1.03-1.08)$ & 0.002 & $1.07(1.05-1.09)$ & $<0.001$ & $1.06(1.03-1.09)$ & $<0.001$ \\
\hline \multicolumn{9}{|c|}{ Non-kidney disease $\left(>60 \mathrm{~mL} / \mathrm{min} / 1.73 \mathrm{~m}^{2}\right)$} \\
\hline CRUSADE $(\times$ point $)$ & $1.06(1.03-1.10)$ & 0.001 & $1.05(1.01-1.08)$ & 0.023 & $1.08(1.04-1.12)$ & $<0.001$ & $1.06(1.02-1.12)$ & 0.010 \\
\hline \multicolumn{9}{|c|}{ Kidney disease $\left(<60 \mathrm{~mL} / \mathrm{min} / 1.73 \mathrm{~m}^{2}\right)$} \\
\hline CRUSADE $(\times$ point $)$ & $1.05(1.01-1.09)$ & 0.008 & $1.02(0.90-1.09)$ & 0.131 & $1.06(1.03-1.11)$ & 0.001 & $1.06(1.01-1.10)$ & 0.021 \\
\hline
\end{tabular}

Adjusted by chronic oral anticoagulation, high-sensitive troponin $\mathrm{T}$, chronic obstructive pulmonary disease, radial access, multivessel disease, percutaneous coronary intervention, glycoprotein IIb/IIIa, enoxaparin/unfractionated heparin switch, and new antiplatelet use (new antiplatelets include prasugrel and ticagrelor). BARC, Bleeding Academic Research Consortium; CRUSADE, Can Rapid risk stratification of Unstable angina patients Suppress ADverse outcomes with Early implementation of the ACC/AHA guidelines; OR, odds ratio.

Fig. 2. Receiver-operating characteristic curves for predicting. a CRUSADE bleeding complications according to kidney function status. b BARC bleeding complications according to kidney function status.

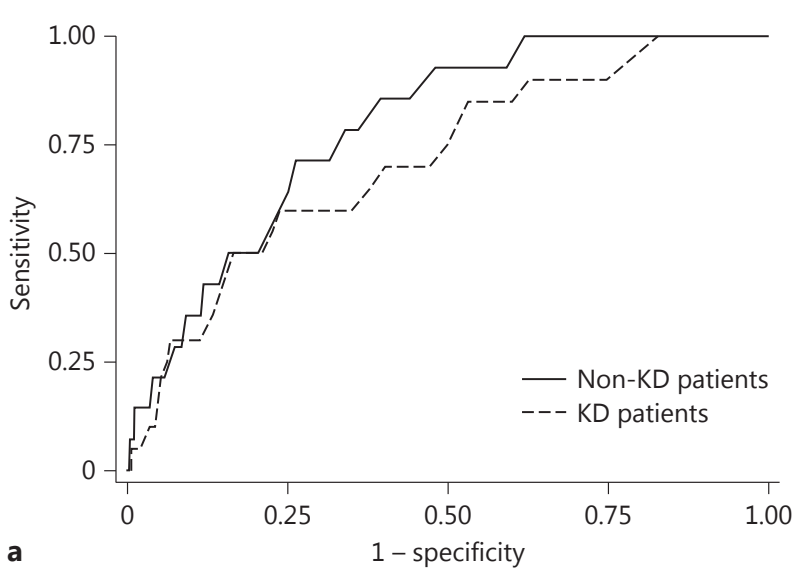

a

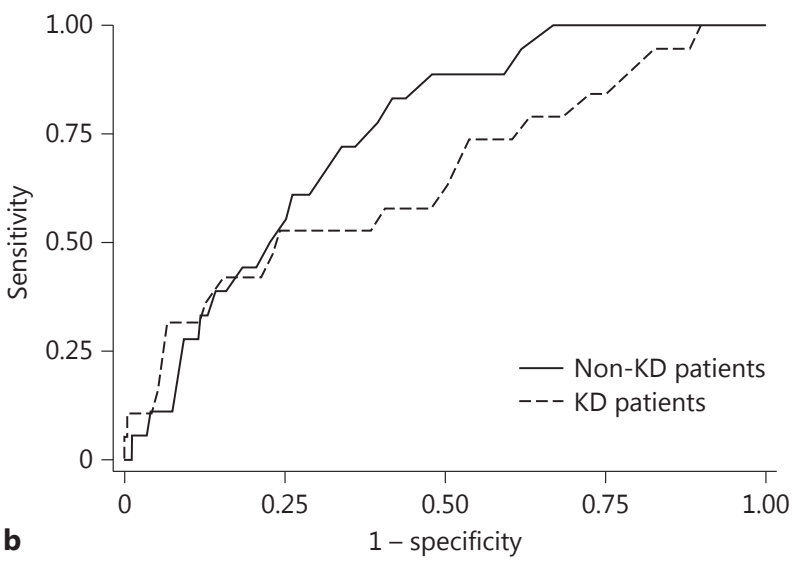

of in-hospital MB, but among patients with KD, it was less powerfully predictive for BARC MB. Our study included $2 \mathrm{MB}$ criteria: the CRUSADE criteria, used for the score development, and the BARC criteria, which are currently recommended in cardiovascular research [16]. Regardless of the bleeding definition used, we found similar results, increasing the value of our study conclusions. Our results are useful in that they are based on a large contemporary cohort of ACS subjects, and they may be helpful to clinicians and clinical trialists alike. 
Bleeding has emerged as an important outcome in the management of ACS. Patients with bleeding in the acute phase of ACS have worse outcomes [2]. There are 2 main hypotheses to explain the relationship between bleeding and adverse outcomes. The former is based on the overlap of bleeding and ischemic risk. This is revealed by the fact that most of the predictors are shared between the CRUSADE bleeding score and the most widely used ischemic risk score, the Global Registry of Acute Coronary Events (GRACE) score [7, 9]. This suggests that bleeding acts as a marker for an increased risk for ischemic events and mortality. A second possibility is that bleeding has direct harmful consequences and also sets in motion a number of deleterious adaptive changes. Primary consequences of bleeding include hypotension, anemia, and reduction in oxygen delivery. All of them have ineludible harmful effects. Secondary consequences include discontinuation of antithrombotic therapy, which places the patient at an increased risk of recurrent ischemic events [17], and blood transfusions with proven detrimental effects [18].

Increased recognition of the prognostic relevance of bleeding has led to the development of therapeutic strategies to avoid bleeding complications [16]. However, in order to apply such strategies to reduce the risk for MB, accurate methods for identifying patients at a higher risk of bleeding complications are needed. Moreover, misclassification of patients in higher bleeding risk categories may reduce the use of certain antithrombotic agents or invasive approaches, at the risk of undertreating patients. In fact, KD patients represent a high-risk population for a reduced use of guideline-recommended therapies, as has been previously reported [11]. In our population, the use of coronary angiography, percutaneous coronary intervention, drug eluting stent, and new antiplatelet agents were lower among KD patients. Although our study was not specifically designed to address the reason for this different clinical management, we assume that high bleeding risk may represent a determinant factor.

As in previous studies, we found KD to be associated with a higher MB risk $[10,11]$. Several factors may be implicated in the relationship between KD and excess bleeding risk. Patients with KD are typically older, more often female, and have more comorbidities associated with a higher bleeding risk [10,19]. Other risks for MB in those with KD include excess anticoagulant therapy [20] and hemostatic dysfunction (including abnormal platelet function); each predisposes KD patients to an increased risk of bleeding [21]. However, on the other hand, a state of hypercoagulation has also been demonstrated in KD patients [22], and a higher rate of ischemic events has been reported [10], thereby illustrating the challenge of caring for such patients, which reinforces the importance of accurate risk assessment in order to match treatment to the likelihood of benefit versus risk.

Several bleeding scores designed to help identify patients at a higher risk for bleeding have been developed during recent years [7, 23, 24]. However, validation of these scores in high-prevalent specific populations is logical. Given that up to $30-40 \%$ of the patients presenting with ACS have some degree of renal insufficiency [10], we consider that our study has important implications. Indeed, Ariza-Solé et al. [25] reported a suboptimal performance of several bleeding risk scores (including the CRUSADE risk score) in elderly patients with ACS. They postulated that fragility and comorbidities could be associated with the worse performance of bleeding risk scores in this population. We obtained similar conclusions among KD patients. Encompassed within these patients were a number of well-established factors associated with a higher bleeding risk, such as advanced age, female sex, and other medical comorbidities associated with an increased bleeding risk [2, 7, 16, 23, 24]. Concurrency of these factors (many of them included in the CRUSADE risk score) among KD patients moves this population to a higher bleeding risk category and inevitably decreases the discriminatory power of this score. Identifying discriminatory bleeding factors could lead to develop specific bleeding scores for KD patients, given the aforementioned relevance of appropriate ischemic-bleeding risk stratification in these patients. 
Sánchez-Martínez et al.: CRUSADE Score in Kidney Dysfunction Patients

A strength of our study is that it was conducted in a contemporary cohort of ACS patients on current therapies (including newer antiplatelet therapies), as there are no previous studies exploring the CRUSADE performance in ACS patients on these drugs. However, the present study has several limitations. It is a retrospective analysis of a prospective registry conducted in a single center, so the applicability of the present results should therefore be viewed with caution in centers with other types of patients and medical facilities and should be considered hypothesis generating. The small sample size and the low number of MB, particularly in the KD group, also make it difficult to draw firm conclusions. However, although a low number of events can limit the statistical precision of ROC curve calculation, we believe that the notable differences seen are not attributable to the small sample size, particularly taking into account the conservative effect of the statistical approach used.

In conclusion, in our series, regardless of the MB definition, the CRUSADE bleeding risk score shows a lower discriminative performance in KD patients compared to those without KD. Further studies are needed to confirm these findings and to explore alternative scores that predict more accurately in-hospital MB in ACS patients with KD.

\section{Statement of Ethics}

The study complied with the Declaration of Helsinki and was approved by the Institutional Review Board of the University Hospital Virgen de la Arrixaca University of Murcia, Spain.

\section{Disclosure Statement}

The authors report no conflicts of interest and take the responsibility for the content and writing of the paper.

\section{References}

1 Fox KA, Steg PG, Eagle KA, Goodman SG, Anderson FA Jr, Granger CB, Flather MD, Budaj A, Quill A, Gore JM; GRACE Investigators: Decline in rates of death and heart failure in acute coronary syndromes, 1999-2006. JAMA 2007;297:1892-1900.

2 Eikelboom JW, Mehta SR, Anand SS, Xie C, Fox KA, Yusuf S: Adverse impact of bleeding on prognosis in patients with acute coronary syndromes. Circulation 2006;114:774-782.

3 Fox KA, Carruthers K, Steg PG, Avezum A, Granger CB, Montalescot G, Goodman SG, Gore JM, Quill AL, Eagle KA; GRACE Investigators: Has the frequency of bleeding changed over time for patients presenting with an acute coronary syndrome? The global registry of acute coronary events. Eur Heart J 2010;31:667-675.

4 Spertus JA, Decker C, Gialde E, Jones PG, McNulty EJ, Bach R, Chhatriwalla AK: Precision medicine to improve use of bleeding avoidance strategies and reduce bleeding in patients undergoing percutaneous coronary intervention: prospective cohort study before and after implementation of personalized bleeding risks. BMJ 2015; 350:h1302.

5 Roffi M, Patrono C, Collet JP, Mueller C, Valgimigli M, Andreotti F, Bax JJ, Borger MA, Brotons C, Chew DP, Gencer B, Hasenfuss G, Kjeldsen K, Lancellotti P, Landmesser U, Mehilli J, Mukherjee D, Storey RF, Windecker S: 2015 ESC Guidelines for the management of acute coronary syndromes in patients presenting without persistent ST-segment elevation: Task Force for the Management of Acute Coronary Syndromes in Patients Presenting without Persistent ST-Segment Elevation of the European Society of Cardiology (ESC). Eur Heart J 2016;37: 267-315

6 Steg PG, James SK, Atar D, Badano LP, Blömstrom-Lundqvist C, Borger MA, Di Mario C, Dickstein K, Ducrocq G, Fernandez-Aviles F, Gershlick AH, Giannuzzi P, Halvorsen S, Huber K, Juni P, Kastrati A, Knuuti J, Lenzen MJ, Mahaffey KW, Valgimigli M, van't Hof A, Widimsky P, Zahger D: ESC Guidelines for the management of acute myocardial infarction in patients presenting with ST-segment elevation. Eur Heart J 2012;33:2569-2619.

7 Subherwal S, Bach RG, Chen AY, Gage BF, Rao SV, Newby LK, Wang TY, Gibler WB, Ohman EM, Roe MT, Pollack CV Jr, Peterson ED, Alexander KP: Baseline risk of major bleeding in non-ST-segment-elevation myocardial infarction: the CRUSADE (Can Rapid risk stratification of Unstable angina patients Suppress ADverse outcomes with Early implementation of the ACC/AHA Guidelines) bleeding score. Circulation 2009;119:1873-1882. 
8 Ariza-Solé A, Sánchez-Elvira G, Sánchez-Salado JC, Lorente-Tordera V, Salazar-Mendiguchía J, Sánchez-Prieto R, Romaguera-Torres R, Ferreiro-Gutiérrez JL, Gómez-Hospital JA, Cequier-Fillat A: CRUSADE bleeding risk score validation for ST-segment-elevation myocardial infarction undergoing primary percutaneous coronary intervention. Thromb Res 2013;132:652-658.

9 Moscucci M, Fox KA, Cannon CP, Klein W, López-Sendón J, Montalescot G, White K, Goldberg RJ: Predictors of major bleeding in acute coronary syndromes: the Global Registry of Acute Coronary Events (GRACE). Eur Heart J 2003;24:1815-1823.

10 Al Suwaidi J, Reddan DN, Williams K, Pieper KS, Harrington RA, Califf RM, Granger CB, Ohman EM, Holmes DR Jr; for the GUSTO-IIb, GUSTO-III, PURSUIT, and PARAGON-A Investigators: Platelet IIb/IIIa antagonism for the reduction of acute coronary syndrome events in a global organization network. Prognostic implications of abnormalities in renal function in patients with acute coronary syndromes. Circulation 2002;106:974-980.

11 Reddan DN, Szczech L, Bhapkar MV, Moliterno DJ, Califf RM, Ohman EM, Berger PB, Hochman JS, Van de Werf F, Harrington RA, Newby LK: Renal function, concomitant medication use and outcomes following acute coronary syndromes. Nephrol Dial Transplant.2005;20:2105-2112.

12 Mehran R, Rao SV, Bhatt DL, Gibson CM, Caixeta A, Eikelboom J, Kaul S, Wiviott SD, Menon V, Nikolsky E, Serebruany V, Valgimigli M, Vranckx P, Taggart D, Sabik JF, Cutlip DE, Krucoff MW, Ohman EM, Steg PG, White H: Standardized bleeding definitions for cardiovascular clinical trials: a consensus report from the Bleeding Academic Research Consortium. Circulation 2011;123:2736-2747.

13 Levey AS, Stevens LA, Schmid CH, Zhang YL, Castro AF 3rd, Feldman HI, Kusek JW, Eggers P, Van Lente F, Greene T, Coresh J; CKD-EPI (Chronic Kidney Disease Epidemiology Collaboration): A new equation to estimate glomerular filtration rate. Ann Intern Med 2009 5;150:604-612.

14 DeLong ER, DeLong DM, Clarke-Pearson DL: Comparing the areas under two or more correlated receiver operating characteristic curves: a nonparametric approach. Biometrics 1988;44:837-845.

15 Lemeshow S, Hosmer DW Jr: A review of goodness of fit statistics for use in the development of logistic regression models. Am J Epidemiol 1982;115:92-106.

16 Steg PG, Huber K, Andreotti F, Arnesen H, Atar D, Badimon L, Bassand JP, De Caterina R, Eikelboom JA, Gulba D, Hamon M, Helft G, Fox KA, Kristensen SD, Rao SV, Verheugt FW, Widimsky P, Zeymer U, Collet JP: Bleeding in acute coronary syndromes and percutaneous coronary interventions: position paper by the Working Group on Thrombosis of the European Society of Cardiology. Eur Heart J 2011;32:1854-1864.

17 Collet JP, Montalescot G, Blanchet B, Tanguy ML, Golmard JL, Choussat R, Beygui F, Payot L, Vignolles N, Metzger JP, Thomas D: Impact of prior use or recent withdrawal of oral antiplatelet agents on acute coronary syndromes. Circulation 2004;110:2361-2367.

18 Kinnaird TD, Stabile E, Mintz GS, Lee CW, Canos DA, Gevorkian N, Pinnow EE, Kent KM, Pichard AD, Satler LF, Weissman NJ, Lindsay J, Fuchs S: Incidence, predictors, and prognostic implications of bleeding and blood transfusion following percutaneous coronary interventions. Am J Cardiol 2003;92:930-935.

19 Mehran R, Nikolsky E, Lansky AJ, Kirtane AJ, Kim YH, Feit F, Manoukian S, Moses JW, Ebrahimi R, Ohman EM, White HD, Pocock SJ, Dangas GD, Stone GW: Impact of chronic kidney disease on early (30-day) and late (1-year) outcomes of patients with acute coronary syndromes treated with alternative antithrombotic treatment strategies: an ACUITY (Acute Catheterization and Urgent Intervention Triage strategY) substudy. JACC Cardiovasc Interv 2009;2:748-757.

20 Alexander KP, Chen AY, Roe MT, Newby LK, Gibson CM, Allen-LaPointe NM, Pollack C, Gibler WB, Ohman EM, Peterson ED; CRUSADE Investigators: Excess dosing of antiplatelet and antithrombin agents in the treatment of non-ST-segment elevation acute coronary syndromes. JAMA 2005 28;294:3108-3116.

21 Jalal DI, Chonchol M, Targher G: Disorders of hemostasis associated with chronic kidney disease. Semin Thromb Hemost 2010;36:34-40.

22 Stam F, van Guldener C, Schalkwijk CG, ter Wee PM, Donker AJ, Stehouwer CD: Impaired renal function is associated with markers of endothelial dysfunction and increased inflammatory activity. Nephrol Dial Transplant 2003;18:892-898.

23 Mehran R, Pocock SJ, Nikolsky E, Clayton T, Dangas GD, Kirtane AJ, Parise H, Fahy M, Manoukian SV, Feit F, Ohman ME, Witzenbichler B, Guagliumi G, Lansky AJ, Stone GW: A risk score to predict bleeding in patients with acute coronary syndromes. J Am Coll Cardiol 2010;55:2556-2566.

24 Mathews R, Peterson ED, Chen AY, Wang TY, Chin CT, Fonarow GC, Cannon CP, Rumsfeld JS, Roe MT, Alexander KP: In-hospital major bleeding during ST-elevation and non-ST-elevation myocardial infarction care: derivation and validation of a model from the ACTION Registry ${ }^{\circledR}$-GWTG ${ }^{\mathrm{TM}}$. Am J Cardiol 2011;107:1136-1143.

25 Ariza-Solé A, Formiga F, Lorente V, Sánchez-Salado JC, Sánchez-Elvira G, Roura G, Sánchez-Prieto R, Vila M, Moliner P, Cequier A: Efficacy of bleeding risk scores in elderly patients with acute coronary syndromes. Rev Esp Cardiol (Engl Ed) 2014;67:463-470. 